\title{
Implementasi Booklet Nata Kulit Semangka bagi Petani untuk Meningkatkan Pengetahuan dan Keterampilan
}

\author{
Umu Fatonatul Hidayah ${ }^{1}$, Utami Sri Hastuti ${ }^{2}$, Sueb $^{2}$ \\ ${ }^{1}$ SMA N 1 Puncu \\ ${ }^{2}$ Pendidikan Biologi-Universitas Negeri Malang
}

\begin{tabular}{l}
\hline INFO ARTIKEL \\
\hline Riwayat Artikel: \\
Diterima: 08-02-2019 \\
Disetujui: 17-07-2019 \\
\hline
\end{tabular}

\section{Kata kunci:}

booklet;

knowledge;

skills;

booklet;

pengetahuan;

keterampilan

\begin{abstract}
ABSTRAK
Abstract: This research developed a booklet of Nata from watermelon rind to improve farmers' knowledge and skills. This research was a development research based on the model of Hannafin \& Peck (1988). Booklet were implemented through counseling to farmers in the village of Klampisan, Kandangan Subdistrict, Kediri Regency. The results showed that after the extension and training activities there was an increase in knowledge. The average score of the $\mathrm{N}$-gain results is 0.66 and is in the medium category. The results of the t-test show the value of $\mathrm{p}=0,000<0,05$, meaning that there is an increase in knowledge about the nata of watermelon peel. Farmers' skills in making nata were assessed using an observation sheet. The average value obtained is 93.7 with a very good category.
\end{abstract}

\begin{abstract}
Abstrak: Penelitian ini mengembangkan Booklet Nata dari Kulit Semangka bagi petani untuk meningkatkan pengetahuan dan keterampilan mereka. Penelitian ini merupakan penelitian pengembangan berdasarkan model Hannafin \& Peck (1988). Booklet diimplementasikan melalui penyuluhan kepada para petani di desa Klampisan Kecamatan Kandangan Kabupaten Kediri. Hasil penelitian membuktikan peningkatan pengetahuan terjadi setelah adanya penyuluhan. Skor rata-rata hasil $\mathrm{N}$-gain adalah 0,66 dan masuk dalam kategori sedang. Hasil uji-t menunjukkan nilai $\mathrm{p}=0,000<0,05$ berarti terdapat peningkatan pengetahuan tentang nata dari kulit semangka. Keterampilan petani dalam membuat nata dinilai dengan menggunakan lembar observasi. Rerata nilai yang diperoleh adalah 93,7 dengan kategori amat baik.
\end{abstract}

\section{Alamat Korespondensi:}

Umu Fatonatul Hidayah

SMA N 1 Puncu

Desa Asmorobangun, Kec. Puncu, Kab. Kediri

E-mail: fathonahummu@gmail.com

Pendidikan berperan penting dalam pembangunan Indonesia, tetapi kurikulum lembaga pendidikan formal kurang mampu menyelesaikan permasalahan yang ada di masyarakat. Pendidikan nonformal merupakan penunjang dan pelengkap pendidikan formal (Tudor, 2013). Pendidikan nonformal mencakup semua pembelajaran dan pelatihan di luar institusi pendidikan formal (Jumani, Rahman, \& Bibi, 2011). Pendidikan nonformal perlu dikembangkan, terutama bagi masyarakat yang tidak mendapat kesempatan untuk melanjutkan pendidikan formal sampai ke jenjang sekolah menengah atas akibat masalah ekonomi keluarga atau cara pandang terhadap pentingnya pendidikan.

Pendidikan nonformal ditujukan untuk mengembangkan kemampuan peserta didik melalui pendidikan keterampilan dan pelatihan sehingga masyarakat lebih berdaya (Permendikbud no 81 tahun 2013). Pendidikan nonformal dipandang relevan dan fleksibel dalam memberikan kontribusi nyata terhadap pembangunan (Kedrayate, 2012). Pendidikan nonformal dapat dilakukan dengan berbagai cara salah satunya melalui penyuluhan kelompok tani. Menurut UU nomor 16 tahun 2006, penyuluhan merupakan proses pembelajaran dan pelatihan agar masyarakat mampu meningkatkan pendapatan dan kesejahteraan, serta meningkatkan kesadaran dalam melestarikan lingkungan hidup. Program pendidikan nonformal diharapkan mampu menanggulangi kemiskinan dengan cara peningkatan wawasan, pengetahuan, dan keterampilan lewat penyuluhan kepada peserta didik (Raharjo, Suminar, \& Mu'arifuddin, 2016).

Penulis melakukan analisis kebutuhan di kelurahan Klampisan Kecamatan Kandangan Kabupaten Kediri pada bulan November 2017. Analisis kebutuhan dilakukan melalui penyebaran angket dan wawancara kepada 20 orang petani. Berdasarkan hasil analisis kebutuhan diketahui, para petani memerlukan penyuluhan untuk menambah wawasan, pengetahuan, dan keterampilan. Petani belum mengetahui bahwa limbah kulit semangka dapat diolah menjadi sesuatu yang berguna, salah satunya diolah menjadi nata. Nata merupakan lembaran gel di permukaan medium hasil fermentasi dari bakteri Acetobacter xilinum. Nata bermanfaat bagi kesehatan karena mengandung serat yang tinggi dan mengandung kalori yang rendah sehingga baik bagi pencernaan karena mengaktifkan gerak peristaltik usus sehingga mencegah sembelit dan dapat dimanfaatkan sebagai makanan diet rendah kalori (Sutarminingsih, 2004). Nata dari kulit semangka merupakan satu usaha diversifikasi pangan yang 
mampu meningkatkan ekonomi petani melalui kegiatan wirausaha. Selain itu, dapat mengurangi pencemaran lingkungan akibat pembuangan limbah kulit semangka. Media pembelajaran yang tepat dan sesuai akan mempermudah penyampaian materi dalam penyuluhan. Booklet dengan judul "Nata dari Kulit Semangka, Minuman Sehat Kaya Serat", dapat dipakai dalam penyuluhan kepada petani sebagai upaya untuk meningkatkan pengetahuan dan keterampilan. Booklet terbukti meningkatkan pengetahuan karena booklet memiliki banyak kelebihan, antara lain memakai bahasa yang sederhana dan diperjelas dengan gambar (Parwiyati, Sumekar, \& Mardiningsih, 2014).

\section{METODE}

Booklet dikembangkan dari penelitian eksperimen pembuatan nata dari kulit semangka dengan dua varietas semangka dan tiga macam gula. Hasil penelitian eksperimen pembuatan nata dari kulit semangka digunakan sebagai materi booklet. Booklet dipakai sebagai media pembelajaran untuk penyuluhan bagi para petani. Booklet dibuat dengan model pengembangan Hannafin \& Peck (1998) yang terdiri dari tiga tahap, yaitu analisis kebutuhan (needs assesment), desain (design) dan tahap mengembangkan/menerapkan (develop/implement). Secara lengkap susunan isi booklet dapat dilihat pada tabel 1.

Tabel 1. Susunan Lengkap Isi Booklet

\begin{tabular}{|c|c|c|}
\hline No & Struktur Isi & Penjabaran \\
\hline 1 & Judul & "Nata dari kulit semangka, minuman sehat kaya serat". \\
\hline 2 & Halaman awal & Kata pengantar dan daftar isi \\
\hline 3 & Bab I & $\begin{array}{l}\text { Mengenal semangka } \\
\text { Prospek pemanfaatan kulit semangka menjadi nata } \\
\text { Nata sebagai minuman kesehatan }\end{array}$ \\
\hline 4 & Bab II & $\begin{array}{l}\text { Alat dan bahan untuk membuat nata dari kulit semangka } \\
\text { Langkah pembuatan nata dari kulit semangka } \\
\text { Pengolahan nata dari kulit semangka } \\
\text { Cara penyajian nata dari kulit semangka }\end{array}$ \\
\hline 5 & Bab III & $\begin{array}{l}\text { Teknik pengemasan nata dari kulit semangka. } \\
\text { Strategi dan teknik pemasaran nata dari kulit semangka } \\
\text { Rincian biaya pembuatan nata dari kulit semangka }\end{array}$ \\
\hline 6 & Penutup & Daftar rujukan, glosarium dan biodata penulis \\
\hline
\end{tabular}

Selanjutnya booklet divalidasi oleh validator ahli materi, ahli media pembelajaran dan uji keterbacaan oleh 10 orang petani. Skor dari masing-masing validator diperoleh dengan menggunakan rumus:

$$
\mathrm{P}=\frac{\sum \mathrm{x}}{\sum \mathrm{xi}} \mathrm{X} 100 \%
$$

P merupakan validitas. $\sum X$ merupakan jumlah skor jawaban dalam satu pertanyaan. $\sum X i$ merupakan jumlah skor ideal dalam satu pertanyaan. Hasil persentase validitas dipakai acuan untuk merevisi booklet. Kriteria validasi dapat dilihat pada tabel 2.

Tabel 2. Kriteria Validasi Booklet

\begin{tabular}{ll}
\hline Kriteria (\%) & \multicolumn{1}{c}{ Tingkat Validitas } \\
\hline $85,01-100$ & Sangat valid, dapat dipakai dengan sedikit revisi \\
\hline $70,01-85,00$ & Cukup valid, dapat dipakai dengan revisi sedang \\
\hline $50,01-70,00$ & Kurang valid, lebih baik tidak digunakan karena perlu banyak revisi \\
\hline $01,00-50,00$ & Tidak valid, tidak boleh digunakan \\
\hline
\end{tabular}

(Sumber: modifikasi dari Akbar, 2013)

Booklet yang sudah dinyatakan valid oleh validator dipakai sebagai media pembelajaran untuk mengetahui meningkatkan pengetahuan dan keterampilan yang dimiliki petani dalam pembuatan nata dari kulit semangka. Objek penelitian ini adalah 20 orang petani yang menjadi anggota kelompok tani di Kelurahan Klampisan Kecamatan Kandangan. Sebelum dilakukan penelitian, petani diberi penjelasan mengenai manfaat dan tujuan dari penelitian, kemudian responden menandatangani lembar persetujuan (Informed Consent). Data kuantitatif berupa skor pretest dan postest, penilaian terhadap peningkatan pengetahuan menggunakan rumus N-gain (Hake, 1999). Adapun rumus dari N-gain seperti di bawah ini. Kriteria skor hasil N-gain dapat dilihat pada tabel 3. 


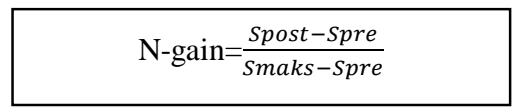

$\mathrm{S}_{\text {post }}$ merupakan skor tes akhir. $\mathrm{S}_{\text {pre }}$ merupakan skor tes awal. $\mathrm{S}_{\text {maks }}$ merupakan skor maksimal.

Tabel 3. Kategori Perolehan Skor N-gain

\begin{tabular}{lc}
\hline \multicolumn{1}{c}{ Rentang } & Kategori \\
\hline $\mathrm{g} \leq 0,3$ & Rendah \\
\hline $0,3<\mathrm{g} \leq 0,7$ & Sedang \\
\hline $0,70<\mathrm{g} \leq 1,00$ & Tinggi \\
\hline
\end{tabular}

(Sumber: Hake, 1999)

Analisis selanjutnya adalah pengolahan data dengan SPSS. Sebelum dilakukan uji beda dengan uji t-tes berpasangan (Paired Sample T-Test), harus dilakukan uji normalitas terlebih dulu dengan Shapiro-Wilk. Keterampilan petani dalam membuat nata dari kulit semangka dengan panduan booklet, diukur dengan lembar observasi. Penilaian keterampilan petani, meliputi tahap persiapan, pembuatan, dan pengolahan nata. Persentase keterampilan dihitung dengan menggunakan rumus di bawah ini. Kriteria nilai akhir dari setiap individu dijabarkan pada tabel 4.

$$
\mathrm{P}=\stackrel{\sum \mathrm{x}}{\sum \mathrm{Xi}}
$$

P merupakan nilai akhir. $\sum$ X merupakan jumlah skor yang diperoleh. $\sum$ Xi merupakan jumlah skor maksimal.

Tabel 4. Kriteria Nilai Akhir

\begin{tabular}{cl}
\hline \multicolumn{1}{c}{ Nilai } & \multicolumn{1}{c}{ Kategori } \\
\hline $91-100$ & Sangat baik \\
$81-90$ & Baik \\
$71-80$ & Cukup \\
$60-70$ & Kurang \\
60 ke bawah & Sangat kurang \\
\hline
\end{tabular}

(Sumber: Sunarti \& Rahmawati, 2013)

\section{HASIL}

Data uji validitas dan uji keterbacaan booklet berupa skor penilaian dalam bentuk persentase. Ringkasan uji validitas oleh ahli materi, ahli media serta uji keterbacaan dapat dilihat pada tabel 5.

Tabel 5. Hasil Uji Validitas Ahli Materi, Ahli Media, dan Uji Keterbacaan

\begin{tabular}{cccc}
\hline No & Aspek Penilaian & Rerata (\%) & Kriteria \\
\hline 1 & Validitas Ahli Materi & 90,32 & Sangat Valid \\
\hline 2 & Validitas Ahli Media & 94,4 & Sangat Valid \\
\hline 3 & Uji Keterbacaan & 90,42 & Sangat Valid \\
\hline
\end{tabular}

Untuk mengetahui peningkatan pengetahuan nata dari kulit semangka yang dimiliki petani maka dipakai rumus N-gain yang hasilnya adalah 0,66 . Selanjutnya, untuk mengetahui perbedaan pengetahuan yang dimiliki petani maka dilakukan uji t-tes berpasangan (paired samples tes). Hasil dari uji t dapat dilihat pada tabel 6 .

Tabel 6. Ringkasan Hasi Uji t-tes Berpasangan

Paired Samples Test

\section{Paired Differences}

\begin{tabular}{|c|c|c|c|c|c|c|c|c|}
\hline & \multirow{2}{*}{ Mean } & \multirow{2}{*}{ Std. Deviation } & \multirow{2}{*}{ Std. Error Mean } & \multicolumn{2}{|c|}{ 95\% Confidence Interval of the Difference } & & \multirow{2}{*}{\multicolumn{2}{|c|}{ df Sig. (2-tailed) }} \\
\hline & & & & Lower & Upper & & & \\
\hline Pair 1 Akhir-awal & 32,000 & 10,052 & 2,248 & 27,295 & 36,705 & 14,236 & 19 & ,000 \\
\hline
\end{tabular}




\section{PEMBAHASAN}

Perkembangan zaman mengharuskan semua warga masyarakat untuk meningkatkan kompetensi diri. Para petani yang tidak sempat belajar di lembaga formal dapat menambah pengetahuan lewat jalur nonformal. Secara khusus, kegiatan penyuluhan bagi petani dapat diartikan sebagai kegiatan dalam pendidikan nonformal yang bertujuan untuk menumbuhkan perubahan diri melalui inovasi baru guna meningkatkan kesejahteraan hidup yang lebih baik. Penyuluhan dilakukan kepada petani dengan menggunakan berbagai macam materi dan media, salah satunya penyuluhan tentang pembuatan nata dari kulit semangka.

Booklet digunakan sebagai media pembelajaran dalam kegiatan penyuluhan bagi para petani. Sebelum dipakai sebagai media pembelajaran, booklet divalidasi oleh ahli materi mikrobiologi, ahli media pembelajaran dan uji keterbacaan oleh para petani. Skor rerata validitas booklet oleh validator ahli materi mikrobiologi adalah 90,32. Validator ahli media memberi nilai dengan skor rerata 94,4. Kevalidan booklet meliputi kelengkapan materi dan penjelasan langkah pembuatan nata, sedangkan komponen kegrafisan, meliputi penggunaan jenis huruf, ukuran huruf, latar belakang gambar, serta tampilan gambar. Hasil pengujian keterbacaan oleh petani juga menunjukkan kriteria sangat valid dengan skor rerata 90,42. Hal tersebut menunjukkan bahwa booklet layak dan dapat digunakan sebagai media pembelajaran dalam kegiatan penyuluhan bagi para petani.

Penilaian peningkatan pengetahuan, dilakukan melalui pretest sebelum pembelajaran dan posttest sesudah pembelajaran. Rerata peningkatan nilai dari pretest dan posttest adalah 32,00. Peningkatan pengetahuan diketahui dari hasil pretest dan posttest yang dianalisis dengan $\mathrm{N}$-gain, hasil yang diperoleh adalah 0,66. Skor tersebut masuk dalam kategori sedang. Peningkatan pengetahuan dapat dianalisis dengan uji t-tes berpasangan (paired samples test). Hasil uji-t menunjukkan nilai $\mathrm{p}=0,000<0,05$, berarti ada perbedaan signifikan pengetahuan nata dari kulit semangka dengan penggunaan booklet.

Keterampilan petani dalam membuat nata dari kulit semangka, memanen dan mengolah kulit semangka dinilai berdasarkan lembar observasi. Adapun rerata nilai yang diperoleh adalah 93,7 dengan kategori sangat baik. Rerata nilai tersebut menunjukkan bahwa masyarakat petani mampu membuat nata dari kulit semangka sesuai dengan tahapan yang ada pada booklet. Selain itu, booklet dengan judul "Nata dari Kulit Semangka, Minuman Sehat Kaya Serat", sangat efektif digunakan sebagai bahan ajar dalam penyuluhan di masyarakat petani. Hal tersebut sejalan dengan penelitian terdahulu bahwa pembelajaran dengan media booklet dapat meningkatkan pengetahuan. Neha dan Jamdade (2018), mengadakan penelitian yang hasilnya adalah booklet efektif dalam meningkatkan pengetahuan mengenai informasi perawatan pasca operasi bedah jantung. Media booklet dapat meningkatkan pengetahuan tentang penyakit scabies kepada peternak kambing sebesar 25,40\% (Parwiyati, Sumekar, \& Mardiningsih, 2014). Ada peningkatan pengetahuan yang signifikan tentang pengetahuan gizi seimbang pada ibu balita setelah diberikan penyuluhan dengan media booklet (Pratiwi \& Puspitasari, 2017). Booklet juga terbukti meningkatkan pengetahuan perawat tentang kesiapsiagaan bencana (Diab \& Mabrouk, 2015). Penelitian lain membuktikan bahwa booklet secara signifikan meningkatkan pengetahuan dan keterampilan pramusaji tentang keamanan kualitas makanan (Varghese, George, \& Nayak, 2013). Pemberian booklet sangat efektif meningkatkan pengetahuan, sikap dan keterampilan masyarakat mengenai cara aman dalam menggunakan tabung gas (Lestari \& Hartono, 2012). Informasi dan materi dari booklet juga efektif meningkatkan pengetahuan perawat anak autis (Vijayarani, Nagarajaiah, Mukesh, Balamurugan, 2016).

Booklet merupakan satu media pembelajaran yang dapat menyampaikan informasi secara efisien dan efektif. Informasi lewat booklet dapat meningkatkan pengetahuan dan keterampilan dalam penangganan demam pada anak (Sirait, Rustina, \& Waluyanti, 2013). Seseorang mendapatkan informasi dari booklet yang dibacanya dan dapat meningkatkan pengetahuan dan keterampilannya serta memengaruhi sikap dan perilakunya dalam bertindak. Semakin sering seseorang membaca maka semakin banyak pengetahuan yang didapatkan. Informasi tentang pembuatan nata dari kulit semangka yang diberikan kepada petani disesuaikan dengan kebutuhan petani berupa penyuluhan dengan menggunakan media booklet. Keterampilan perlu dikuasai agar para peserta didik mampu menguasai keterampilan bekerja (prevocational skill) serta keterampilan hidup (life skill) (Prastowo, 2015).

\section{SIMPULAN}

Booklet yang berjudul "Nata dari Kulit Semangka, Minuman Sehat Kaya Serat", dapat digunakan dalam penyuluhan karena sudah dinyatakan sangat valid oleh validator. Kegiatan penyuluhan dengan media cetak berupa booklet dapat peningkatan pengetahuan dan keterampilan petani dalam pembuatan nata dari kulit semangka. Peningkatan pengetahuan dapat dilihat dari selisih rerata nilai posttest dan pretest sebesar 32,00. Keterampilan membuat nata kulit semangka reratanya adalah 93,7 dengan kategori sangat baik.

Bagi peneliti yang berminat melakukan penelitian yang sejenis disarankan untuk membuat booklet berdasarkan hasil penelitian eksperimen nata dari limbah kulit buah yang lain, menguji keefektifan booklet melalui pengetahuan dan keterampilan yang dimiliki petani dengan menggunakan kelas kontrol.

\section{DAFTAR RUJUKAN}

Akbar, S. (2013). Instrumen Perangkat Pembelajaran. Bandung: PT Remaja Rosdakarya.

Diab, G. M., \& Mabrouk, S. M. (2015). The Effect of Guidance Booklet on Knowledge and Attitudes of Nurses Regarding Disaster Preparedness at Hospitals. Journal of Nursing Education and Practice, 5(9), 15-31.

Hake, R. (1999). Analyzing Change/Gain Scores. USA: Dept. of Physics Indiana University. 
Hannafin, M.J. \& Peck, K. L. (1998). The Design, Development and Evaluation of Instructional Software. New York: Mc. Millan Publishing Company.

Jumani, N. B., Rahman, F., \& Bibi, K. (2011). Potensial of Nonformal Bacic Education Promoting Women Education In Pakistan. International Journal of Instruction, 4(1), 17-32.

Kedrayate, A. (2012). Nonformal Education: Is It Relavant or Obsolete? International Journal of Business, Humanities and Technology, 2(4), 11-15.

Lestari, F., \& Hartono, B. (2012). Peningkatan Pengetahuan dan Keterampilan Masyarakat tentang Cara Aman menggunakan Tabung Gas 3 Kg. Kesmas: National Public Health Journal, 6(5), 225-229.

Neha, A. H., \& Jamdade, V. (2018). An Experimental Study to Assess the Effectiveness of Information Booklet on the Knowledge Regarding Post-Operative Care of Children Undergone Cardiac Surgery in Selected Hospitals of Pune city. International Journal of Applied Research, 4(5),384-387.

Parwiyati, S., Sumekar, W., \& Mardiningsih, D. (2014). Pengaruh Penggunaan Media Booklet pada Peningkatan Pengetahuan Peternak Kambing tentang Penyakit Scabies di KTT Ngupoyo Sato Desa Wonosari Kecamatan Patebon. Animal Agriculture Journal, 3(4), 581-585.

Prastowo, A. (2015). Panduan Kreatif Membuat Bahan Ajar Inovatif. Yogyakarta: Diva Press.

Pratiwi, Y. F. \& Puspitasari, D. I. (2017). Efektivitas Penggunaan Media Booklet terhadap Pengetahuan Gizi Seimbang pada Ibu Balita Gizi Kurang di Kelurahan Semanggi Kecamatan Pasar Kliwon Surakarta. Jurnal Kesehatan, 10(1), 58-67.

Raharjo, T. J., Suminar, T., \& Mu'arifuddin. (2016). Peran Pusat Kegiatan Belajar Masyarakat dalam Menanggulangi Kemiskinan melalui Pendidikan Nonformal di Jawa Tengah. Journal of Nonformal Education, 2(1), 21-39.

Sirait, N. A. J., Rustina, Y., \& Waluyanti, F. T. (2013). Pemberian Informasi Meningkatkan Pengetahuan, Sikap dan Keterampilan Orangtua dalam Penangganan Demam pada Anak. Jurnal Keperawatan Indonesia, 16(2), 101-106.

Sunarti., \& Rahmawati. (2013). Penilaian Dalam Kurikulum 2013. Yogyakarta: Andi Offset.

Sutarminingsih, L. (2004). Peluang Usaha Nata de Coco. Yogyakarta: Kanisius.

Tudor, S. L. (2013). Formal - Non-formal - Informal in Education. Procedia - Social and Behavioral Sciences, 76, 821-826.

Undang-Undang nomor 16 tahun 2006 tentang Sistem Penyuluhan Pertanian, Perikanan, dan Kehutanan.

Varghese, D. M., George, A., \& Nayak, M. G. (2013). Effectiveness of an Information Booklet on Knowledge and Practice on Food Safety Among Food Handlers in Restaurants. International Journal of Advanced Research, 1(8), 767-775.

Vijayarani, M., Nagarajaiah, Mukesh, Balamurugan. (2016). Effectiveness of an Information Booklet on Knowledge Regarding Care of Children with Autistism. International Journal of Nursing, 2(2), 27-35. 